\title{
Oral Reading Fluency: Teaching and Assessment Strategies ${ }^{i}$
}

\author{
Zainab R. Aldhanhani*, Emad A. S. Abu-Ayyash \\ College of Education, British University in Dubai, United Arab Emirates
}

Received April 12, 2021; Revised May 28, 2021; Accepted June 20, 2021

\section{Cite This Paper in the following Citation Styles}

(a): [1] Zainab R. Aldhanhani, Emad A. S. Abu-Ayyash, "Oral Reading Fluency: Teaching and Assessment Strategies," Universal Journal of Educational Research, Vol. 9, No. 7, pp. 1375 - 1384, 2021. DOI: 10.13189/ujer.2021.090704.

(b): Zainab R. Aldhanhani, Emad A. S. Abu-Ayyash (2021). Oral Reading Fluency: Teaching and Assessment Strategies. Universal Journal of Educational Research, 9(7), 1375 - 1384. DOI: 10.13189/ujer.2021.090704.

Copyright $(2021$ by authors, all rights reserved. Authors agree that this article remains permanently open access under the terms of the Creative Commons Attribution License 4.0 International License

\begin{abstract}
Oral reading fluency skill is one of the keys to reading comprehension. Despite the significance of this skill, many reading curricula pay no attention to it [1]. Private schools in the United Arab Emirates (UAE) are giving great attention to reading fluency more than public schools. As a result, the current study adopted the exploratory qualitative design, in which three tools (documents analysis, classroom observations, and interviews) were employed respectively to investigate this issue in two private schools within the UAE. In particular, this study aimed: (1) to identify oral reading strategies used in private schools, (2) to identify the assessment strategies used to assess oral reading fluency, and (3) to identify if there is a match between the reading-aloud strategies and the assessment strategies used. Interestingly, the exploratory design helped to gain well-founded insights about the significance of teaching and assessing this skill. Moreover, the findings revealed English teachers' practices in teaching and assessing students' oral reading fluency. Teachers used plenty of reading-aloud strategies such as repeated reading, pair reading, individual reading-aloud, practice reading, choral reading, reading practice, and assisted reading to build and improve students' reading fluency. It was also obvious that different assessment techniques were employed to assess students' oral reading fluency such as the rubric, checklist, DIBLES: WCPM test, word efficiency test, and keeping records of students' performance. Furthermore, it was clear that the aforementioned assessment tools were suitable with the reading-aloud instruction provided to the students. Notably, this research has contributed to the limited body of knowledge within the UAE about the significance of integrating reading-aloud strategies in any reading
\end{abstract}

programs to develop students' fluency and comprehension. The study bridged the gap in the literature through exploring more than one strategy and more than one assessment tool used to boost students' oral reading fluency. According to the previous findings, fostering oral reading fluency and creating a better reader, who reads fluently should be taken into account. Therefore, oral reading fluency should not be neglected. Policymakers and curriculum designers have to think of incorporating teaching and assessing oral reading fluency into reading programs and curriculum.

Keywords Oral Reading, Fluency, Reading-Aloud Strategies, Assessment Strategies

\section{Introduction}

\subsection{UAE Education System}

The United Arab Emirates is one of the developing Arab countries which is highly focused on its educational system. Therefore, the UAE tries to cope with the changes around the world through continuous changes in its system. In 2015/2016, the education system of the United Arab Emirates was changed massively, and this reform continues. The purpose of this reform is to provide innovative education for all age groups in order to meet future labor market demand, which is stated in the Ministry of Education's (MOE) vision. The MOE seeks to equal educational opportunities for all to create a society that is driven by science, technology and innovation. 
Generally, the education system has two sectors: public and government. Public schools in the UAE follow the MOE curricula and standards, while the private schools follow international standards and curricula such as British and American. Since the main language of the country is Arabic, English is considered to be a foreign language which is taught in both public and private schools. It is significant to point out that private schools concentrate on building and assessing oral reading fluency; however, it is not the case in public schools.

\subsection{Oral Reading Fluency Matters}

Reading is a complex activity that involves different linguistic and cognitive challenges. Interestingly, reading fluency has become a key topic of importance in the ongoing reading instruction debate [1-5]. Usually, fluent readers have the ability to understand the text's meaning without decoding word by word. They sound like native speakers of English when they read aloud [4]. They can read quickly while understanding the meaning of the text. Furthermore, DiSalle and Rasinski [6] claimed that fluent readers have good reading fluency in which they use different intonation, stress some words, and raise their voices when it is needed. Therefore, they speak in a way that helps the audience understand and comprehend. On the other hand, readers, who are struggling with oral reading fluency are likely to have difficulties in accuracy, automaticity, prosody, comprehension, and even silent reading $[3,7]$. Interestingly, many studies showed that non-fluent readers take up too much time and consequently quite a significant amount of mental capacity to comprehend the text [5]. It is also hard for them to recall information. Accordingly, non-fluent readers do not like reading and have a negative attitude toward reading aloud $[2,5,6]$.

It is worth mentioning that oral reading fluency is deeply rooted in literature [1], and there is massive emphasis placed on oral reading fluency at the early stage of school by Ontario [8]. Apparently, there are many reading educators who advocate integrating a balanced reading program that includes various reading techniques to suit different levels and abilities and assessment strategies that help to identify those who have difficulties $[3,6,8,9]$. We live in an era in which people should read quite often in order to cope with the changes around the world. According to Lahmann et al. [2], developing and measuring students' reading fluency regularly could result in building effective reading habits in the new generation.

\subsection{Problem Statement and Rationale}

Based on the researcher's experience over the last ten years (2010-2020) in Fujairah city in the UAE observing high school students in public schools during their examination periods, particularly during English exams, students spend much time decoding word by word and trying to understand the meaning of each word. When the students meet unfamiliar words, they get stuck and, they do not know what to do. In 2019, when the researcher asked some teachers in public schools and looked at the curriculum, it was found that reading fluency is not given clear attention in public schools. However, reading fluency is highly addressed in private schools. Interestingly, in western countries, students have to master oral reading fluency by the end of grade three [3]. Furthermore, in the United States, the ability to read fluently is a skill that all students must master in order to graduate from high school [10]. This situation triggered the researcher's interest in investigating this significant issue in the UAE private schools.

\subsection{Significance, Purpose of the Study and Research Questions}

In fact, oral reading fluency received little focus in the literature that has been conducted in the UAE [11] and Gulf Countries Council (GCC) [12]. According to the consulted literature, no research has yet been conducted about the assessment techniques that are used to assess students' oral reading fluency in the UAE context. Therefore, investigating this issue is very significant and is anticipated to add more value to the research in the UAE context and the literature.

Based on the above reasons, this study has a three-fold purpose: (1) to explore the reading-aloud strategies that teachers use to address students' oral reading fluency in cycles one and two, (2) to explore the assessment strategies used for assessing students' oral reading fluency, and finally, (3) to investigate if there is a match between the reading-aloud strategies and the assessment used. Accordingly, the following questions are created to address the research purpose:

- What are the reading-aloud strategies used?

- What are the assessment strategies/tools used to assess oral reading fluency?

- Is there a match between the reading-aloud strategies and the assessment strategies used?

\section{Theories and Literature}

\subsection{Automaticity Theory}

Aldhanhani and Abu-Ayyash [13] claimed in their study that various studies on oral reading fluency relied on automaticity theory. Based on the automaticity theory, which was introduced by Samuels (1979), there are three essential processes that readers must go through to be fluent. These processes are decoding, comprehension, and attention. Readers should have the ability to decode and comprehend a text. Interestingly, to make students fluent 
readers, Samuels [14] designed a repeated reading strategy. The purpose of the repeated reading strategy is to reduce the capacity for cognition given to decoding text and increase the capacity for comprehension. Consequently, readers will maintain a bigger portion of their mind for understanding [13]. This can happen at an early stage, whereby students, readers, should acquire basic literacy skills such as recognition of letters and sounds to reach to a higher level such as blending. In fact, there are many reading-aloud instructions that involve the repeated reading strategy in which practice and drilling are key factors to all those strategies. Those strategies are choral reading, assisted reading by recorded audio texts, readers theatre, and rhyming poetry strategies.

Needless to mention that assessment is a key element of education used to inform instruction. It is a part of the teaching and the learning processes, as mentioned by Scriven [15]. It is noteworthy that using different reading-aloud instructions without proper assessment could not work. Teachers would not know if students mastered certain skills or not. Therefore, it is important to assess students regularly using various assessments that would assure outcomes. Concerning literacy skills assessments, it is important to highlight that students come from different backgrounds with different levels of knowledge and performance. They also have different learning styles. Therefore, to address their levels and meet their needs, it is essential to determine their abilities and baseline performance by conducting early initial diagnostic reading assessments. The diagnostic assessment provides teachers with students' current levels and informs, assists, their instructions and lesson planning. Moreover, as emphasized by Scriven [15], there are two types of assessment: formative assessment (FA) and summative assessment (SA). Each one has its own functions. The FA is necessary to keep track of students' progress and provide them with appropriate feedback on areas of improvement. In fact, according to Scriven [15], feedback must take place during the FA, whether the feedback is to improve students' progress or the learning process. On the other hand, the SA is conducted at the end of each term, course, to evaluate students. In some exams, students' achievement is assessed against a universal benchmark. Selecting a specific assessment depends on a teacher's purpose. Interestingly, Samuels [14] believed that teachers have to employ various assessment techniques to evaluate students' reading fluency progress, such as observation, rubric, and peer assessment.

\subsection{Studies on Reading-Aloud Strategies and Assessment Strategies}

Reading-aloud strategies have proved their effectiveness in English reading fluency in many studies that have been conducted in first and second language acquisition [16]. It is important to point out that the repeated reading is a ubiquitous strategy in the reading fluency field. For example, Rubin [17] investigated three Mexican American elementary students' development in oral reading fluency (ORF) of Spanish English Language Learners (ELL). The participants had learning difficulties in math and reading, but the author focused only on improving the students' oral reading fluency. The students had to read three selections that focused on phonics, sight phrases, and oral reading passages for sixty seconds. The program focused on two strategies; repeated reading and correcting students' mistakes. The intervention was used daily for seven to eight minutes with each student. The students then were assessed using the WCPM test twice in September 2014 and May 2015 to measure the students' reading rate and automaticity. The results of the pretest and posttest were analyzed by using a t-test to measure the difference before and after using the Intervention program. Significantly, the findings showed a significant increase in students' oral reading fluency scores in the WCPM test.

Additionally, Al-Kharusi [18] investigated the impact of the repeated reading strategy on reading fluency, accuracy, and speed rate in Oman through a quasi-experimental design followed by interviewing participants. The treatment, which was the repeated reading technique, was used for eight weeks with the experimental group. The researcher used WCPM test to measure students' accuracy and speed rate. The post-test results showed that students in the experimental group had better results in reading fluency than the control group. Similarly, Gorsuch and Taguchi [19] conducted a similar study on English as a Foreign Language (EFL) and found the same results. A very interesting study that used different forms of repeated reading is from Berg and Lyke [20], who conducted action research on fifth and sixth-grade students in Northern Illinois. Berg and Lyke [20] were interested in improving students' reading fluency rate, mainly oral reading. They used the repeated reading strategy as an intervention with thirty-eight students for ten weeks. Notably, the teacher used various forms of repeated reading; modeling, and partner reading along with choral reading and error correction with feedback. The results of the WCPM test presented a significant change in students' scores. Interestingly, it is believed that incorporating short poems allows students to read for pleasure [21]. Therefore, students build their confidence in being successful readers. In fact, a daily dose of poetry will strengthen students' reading fluency for all students at different levels. For instance, Calo et al. [22] introduced to her second-grade students a model called "Fluency Idol" to improve their oral reading fluency. The results of the Dynamic Indicators of Basic Early Literacy Skills (DIBELS) ORF showcased great effects on students' oral reading fluency including, rate and automaticity, along with comprehension. The students and their parents had a positive impression of the Fluency Idol model. Notably, the Fluency Idol strategy integrated 
strategies other than rhyming poetry. The model highlighted repeated reading, practice, modeling, and reading theatre strategies. A similar study to this was conducted by Marcell and Ferraro [23], who also used the same model and the same assessment, but with different poems and the results of the study showed the effectiveness of the Fluency Idol strategy.

Furthermore, Black [24] investigated the effectiveness of the reader's theatre strategy on students' reading fluency rate and reading comprehension. Black adopted a quasi-experimental design to find out if using a readers theatre strategy on a weekly basis: three to four times per week with both high and low achievers, who have reading disabilities, would or would not increase fifth-graders reading performance. Fifty students, twenty-five in each, participated in the study. The treatment, a readers theatre strategy, was implemented for nine weeks. A pretest-posttest comparison group design was conducted before and after the treatment. Two tests were used: (a) DIBELS to measure students' reading fluency and (b) the Standardized Test for Assessment of Reading (STAR) to measure students' reading comprehension. A $t$-test was used to analyze the results of the pre-and post-test scores. The results for the oral reading fluency test between the control and experimental groups showed no significant gain in the score; however, the study recommended using the reader's theatre strategy to improve students' fluency not comprehension. Faatz [25] conducted a similar study using the reader's theatre strategy to improve her four students' (who were classified as below grade level) reading fluency and comprehension. The researcher used the reader's theatre strategy for five weeks. Also, two tests were used to assess students' fluency and comprehension, which were: Rasinski's Multidimensional Fluency Scale and the Comprehension Rubric for Story Retellings. Equal to Black's [24] study, Faatz's study outcome [25] was not conclusive; however some of the participants, students, progressed slightly in the Multidimensional Fluency Scale (MFS) scores. Interestingly, Faatz [25] triangulated the data gathered from the three assessment tools; observation, the running reading record, the audiotape recordings, and the MFS to assess students' reading thoroughly. This indicates that using multiple assessment tools is required to assess student's reading fluency, which is noted by Samuels [14] and Rasinski [26].

Rowen et al. [27] conducted a project using a mixed-methods design on twenty-one third-grade students to investigate the effect of choral reading theatre (CRT) on students' reading fluency, including accuracy, automaticity, prosody, and comprehension. Before starting the project, diagnostic assessments were administered to the third graders in a primary school to find out about their previous knowledge related to the topic. The teacher modeled the reading for the students, and the students read and sang in unison as well as acted out the script. The teacher sat with each group reading the text aloud for them. The students had to practice and read aloud after the teacher. Interestingly, the teacher used many assessment tools: WCPM test, observation, taking notes, and keeping a daily record of students' progress. The results of both qualitative and quantitative numerical data showed a significant positive increase in students' reading rate and word recognition. Additionally, it was observed that the prosodic reading of the students was clearly improved.

With respect to the paired reading strategy, Schneider [28] investigated the effect of the paired reading strategy on students' reading fluency and comprehension skills. Three participants participated in the study who were below average in reading. The results of the WCPM test presented that the student's reading fluency and comprehension skills were improved, which indicated the effectiveness of the paired reading strategy. Likewise, Gerdes [29] studied the effect of three reading-aloud strategies: paired reading, repeated reading, and modeling on elementary students, third graders. The outcomes of the WCPM test showed a positive impact on students' reading fluency and comprehension. Overall, there are a variety of reading-aloud strategies and assessment strategies that teachers can use to foster students' oral reading fluency.

\section{Research Methodology}

\subsection{Instruments, Sites, Sampling Methods, and Participants}

To answer the research questions, this study adopted the qualitative design, chiefly the exploratory design. More than one instrument was used to understand the problem more holistically and enhanced the accuracy of the results. Document analysis, classroom observation, and interviews were used respectively to collect in-depth data to understand how oral reading fluency was being taught and assessed. The current study took place in two private schools in Fujairah city in the UAE. The selection of the schools was based on their willingness to support the research. One school followed an American curriculum, and the other followed a British curriculum.

The purposive sample was used and implemented to collect accurate data and meet the study purpose and objectives. The researcher selected English teachers in private schools to gain in-depth data and knowledge about the strategies that were being used to build, improve and assess the student's oral reading fluency. The selection of participants was also based on their willingness to be a part of the study. Cycle one, grades one to six, and cycle two, grades seven to nine, had greater emphasis on the students' reading fluency than cycle three, grades: ten to twelve. Accordingly, fourteen English teachers in the first two cycles were selected. In terms of the sample size for the qualitative part, the number of observed classes was fourteen; eight classes (each class has 25 students) from 
school A and six classes (each class has 25 to 30 students) from school B. Consequently, the same number of interviews was conducted. Consequently, according to Creswell [30], the numbers were suitable for the study. Considering the ethical issue of the research, the anonymity of school sites and participants was protected. There was no description of the school and participants in any way that would allow internal or external personnel to identify any of them. Instead, letters were used to refer to the schools.

\subsection{Data Collection Procedures}

The researcher began by looking at the students' English textbooks in both schools for grade four, which were selected for exploration. Reading-aloud strategies and assessment strategies of oral reading fluency were investigated in the students' textbooks and the lesson plans. Notably, the researcher could not get all of the lesson plans of the observed classes due to the sensitivity of the teachers towards their job security. A total number of 9 lesson plans were received: five lesson plans from school A and four from school B. Significantly, a pilot study was conducted on four English teachers in two private schools in Fujairah city before the actual study to create and test the checklists and to explore more about the reading fluency instruction and assessment techniques that affect students' oral reading fluency. The exploration of the previous variables, reading fluency strategies, and assessment techniques provided the researcher with more ideas and strategies that were not foreseen before conducting the pilot study, which helped the researcher to reform the created checklists.

The two checklists were created by the researcher to investigate the documents. They were prepared based on the research questions and literature reviews. The checklists were meant to help the researcher to analyze the documents qualitatively and control her bias to focus on the issue under investigation. The checklists were used to investigate reading-aloud instructions and assessment techniques that were used for oral reading fluency. Hence, there are a few differences between the checklist guide used to analyze the students' textbooks and the lesson plans. The textbook guide has a title at the top of the page followed by some introductory details, such as the grade level, name of the textbook, authors, publisher, year of publishing, and type of books: language book or workbook. The body of the guide has the variables: reading-aloud strategies and oral reading assessment techniques. For each variable, some key items written on the guide page are given a letter to facilitate taking notes during the analysis process. There are three columns in the body of the guide: the first column presents the variables, the second column illustrates the page number and details about the investigated variables, and the third column is for comments. One row is added for miscellaneous; any valuable point that the researcher did not think of. While the checklist guide for the lesson plans also has a title at the top of the page followed by grade level, lesson plan title, time, duration, and boys/girls class. The body of the checklist also has two variables: reading-aloud strategies and oral reading assessment techniques. For each variable, there are the same key terms or sub-variables as in the checklist for the textbooks. There are five columns in the body of the guide: the first column presents the variables, and the last column presents comments. The three columns in the middle represent the parts of a lesson.

After analyzing the documents, the researcher started to visit and observe English reading classrooms and to conduct interviews with the schools' English teachers based on the prepared schedule. In school A, a class from grade one to nine was observed except for grade six. While in school B, grade-one, five and nine were not observed because the teachers were uncomfortable being observed. The researcher also created a checklist guide for classroom observations, which identified the reading-aloud strategies such as repeated reading, choral reading, and modeling strategies, and the assessment techniques such as rubrics, observations, and WCPM tests. The checklist has some preliminary details such as grade level, day and date, time, class duration, and the number of students. The body of the checklist has a table that consists of seven columns and four rows. The first columns represent the variables in addition to a row for miscellaneous. The next five columns illustrate the class time divided into five periods; each period is ten minutes. The final column is for comments. Letters that represent the sub-variables, written under the table, were used to fill the checklist. The completed checklists were sent to the observed teachers to get their confirmation of the collected data.

The interviews were conducted face to face after classroom observations. They lasted between fifteen and twenty minutes long. Fourteen interviews were conducted with the observed teachers. The researcher started the interview by thanking the interviewees for the time they allocated, informing them about the research goals, and reading the conditions of participation. The researcher then proceeded by asking questions. At the end of the interview, the researcher asked them to sign the consent form. Notably, the interview responses were also sent to the teachers to confirm the collected data and avoid any bias during the interpretation process.

\subsection{Data Analysis}

Documents, students' English textbooks and the lesson plans were analyzed through content thematic analysis to figure out how oral reading fluency was being addressed in the school textbooks and the teachers' practices. Clues for reading fluency instructions were investigated and reported using qualitative content analysis to present 
reading-aloud strategies and assessment techniques in the documents. The observation was selected as a tool to observe and obtain factual data about the oral reading strategies and the assessment strategies that were used in reading classes. It was also used to confirm the collected data from the document analysis and to check if there was consistency between the documents and the actual practices. As such, the analysis of the obtained data was totally qualitative. The themes that were used included reading strategies and assessment strategies. Based on Creswell [30], the qualitative content analysis is the best tool to analyze interviews. Hence, the qualitative content analysis was used, in which again themes were used to identify the variables from the interviews.

\section{Results and Discussion of the Findings}

The following paragraphs present a discussion of the results, which has been organized according to the research questions.

\subsection{What are the Reading-Aloud Strategies Used to Address Oral Reading Fluency?}

The document analysis presented reading-aloud strategies that have shown great influence on students' oral reading fluency such as peer reading, reading together (choral reading), modeled reading, reading with the help of technology, and teachers reading to students, which was found basically in the primary levels lesson plan. Padak and Rasinski [31] and Rasinski [3] recommended using the previous strategies with elementary levels to foster their reading fluency skills. Furthermore, the documents showed that the two schools: A and B, encouraged independent reading, individual reading-aloud, and reading practice to help students build their reading fluency and confidence. Ehri and McCormick [32] also stressed highly in their theory the role of practice in developing reading words. Practice provided the students with opportunities to get exposure to richer language, which allowed them to move gradually towards native-speaker fluency in both oral and written language [3]. Moreover, technology was highly involved in the textbooks and lesson plans, particularly in School A, in which audio and video stories and texts were usually used as a part of reading fluency instructions in the student's textbooks. Students had to listen to an audio text or listen and watch a story.

The classroom observations served as a complementary tool for document analysis. They revealed more reading-aloud strategies than what has been found in the document analysis. In fact, it was visible that the students were given daily chances to read aloud and practice. Apparently, there were more reading-aloud strategies used in cycle one than in cycle two. The reading techniques differed noticeably, albeit slightly at times from one grade to another. For example, most of the teachers, who read and modeled the reading for their students, were in grades one, two and three. They also used repeated reading, group reading with low-level students, and choral reading with all students. For grades four, five and six, the teachers relied more on the students themselves to read to the whole class, along with paired reading. Moreover, with students at lower levels, the teachers employed paired, grouped, and repeated reading techniques. A pertinent conclusion could be drawn that students of a younger age require more deliberate, hands-on support in reading on the part of the teacher [32]. This indicated why the aforementioned strategies were most suitable for them $[5,32]$. On the other hand, in the case of students at age 9 (grade four) and above, they were able to perform well independently. Consequently, the teachers used other techniques, such as a student reading to a group or whole class, paired reading, and group reading. In fact, at the age of 9 , the cognitive and reading abilities should have developed, and therefore, students start focusing on understanding texts. However, the literature has supported all the previous strategies to address students' oral reading fluency not only in primary grades but also with upper grades $[3,4,9,17,18,31,33,34,35,36]$. It is worth mentioning that many of those studies also focused on improving the oral reading fluency of students' who had learning difficulties or special needs. This means that those strategies work well with all students.

On the other hand, for cycle two students, it was clear that the students read aloud throughout the initial periods of the classes. They tended to be independent. It was visible that some students read aloud to the whole class, and sometimes, they read to small groups. The job of the teacher was to correct and model the native speaker of English or native-like pronunciation of the more difficult words to the students as noted by Rasinski [3], Padak and Rasinski [31] and Tankersley [37]. Also, it was clear that there were less reading-aloud strategies used in cycle two, and students were modeling the reading to their classmates. The reason for that is that students in the upper grades should have already developed their reading fluency skills. Therefore, at this level, most of the attention was placed on improving comprehension skills as was claimed by Rasinski [3] and Samuels [14]. However, for students who lack reading fluency, the teachers employed repeated reading, choral reading and reading practice strategies, which were found to develop students' reading fluency.

Additionally, with respect to the pedagogical methods, those employed in various schools are similar in most of the classes. For instance, teachers in School A were using similar academic strategies such as peer reading, choral reading, modeled reading, reading with the help of technology, and teachers reading to students. This applied to school B as well. Notably, the techniques that were 
used with cycle two students were widely used in the literature too, not only for cycle two students but even with higher-level students, such as the repeated reading strategy [38-43]. This indicated the effectiveness of the previous reading-aloud instructions in cycles one and two.

The interviews revealed a wide range of strategies that the English teachers used and believed had a positive impact not only on students' fluency skills such as pronunciation, phonological awareness, accuracy, reading speed, and confidence but also on their comprehension skills as stated by Padak and Rasinski [31]. Those strategies were: model reading, rhyming poetry, assisted reading (watching a video and following the subtitles or listening to an audio file and following with their fingers), individual reading-aloud (one student read to the whole class or one group), paired reading (one high-level student with a below level student), and choral reading (one group of students or the whole class read the text together). These aforementioned strategies are presented in the literature as common techniques that improved students' reading fluency in different countries and at various teaching levels by Rasinski [3], Rasinski and Padak [4], Samuels [14], Rubin [17], Al-Kharusi [18], Berg and Lyke [20], Padak and Rasinski [31], Blevins [33], Meeks and Austin [34], Rasinski et al. [35], and finally Wallot, Van Rooij and Hollis [36].

Furthermore, according to the interview responses, almost all the interviewed teachers used and agreed that integrating technology in the reading instructions can help students in improving their oral reading fluency. For example, they claimed that the repetitive language presented in specific applications on tablets or computers helped the students to acquire the language and improve their pronunciation and fluency, which is supported by Aldhanhani [44] and Reichenberg [45]. Moreover, the eighth interviewee from school (A) used an audio recorder in the class. When she was asked about the reason, she said: "even this device is very simple and not modern, but it has its own advantages. It can make the students confident and fluent". This claim is highlighted by Armbruster et al. [46], who focused on building literacy skills using audio-assisted reading and by Count [47], who used a voice recognition software to develop student's oral reading fluency.

\subsection{What are the Assessment Strategies That are Used for Evaluating Students' Oral Reading Fluency?}

Through the investigation of the document analysis, it was found that both schools emphasized assessing students' oral reading fluency highly. However, there were many tools used in school A, such as rubrics, peer-assessments, self-assessments, and the WCPM test. Clearly, those tools in school A textbooks, in which anyone who read the instructions could implement them. On the other hand, in school B, peer and self-assessments were mentioned in the lesson plans only. However, the lesson plans were not clear enough about how peer and self-assessments were implemented. The lesson plans did not show clear instructions for assessments. When the teachers in school B were asked about the instructions on lesson plans, they claimed that they are knowledgeable teachers who know how to assess. The plan is just to help them. With respect to those tools used, Rasinski [3] encouraged using a variety of techniques and tools to assess and measure oral reading fluency. It depends on the teachers' goals and objectives to use the right assessment tool [43].

Moreover, during the classroom observations, it was found that the teachers depended greatly on observation as a tool to diagnose and assess students' oral reading fluency [26]. It was also observed that the teachers used a rubric to assess students' oral reading rate and prosody, which is stressed by many educators $[26,48,49]$. For example, Xu [48] and Yoon [49] used a rubric for assessing students' expressive reading. It was also visible that peer and self-assessments were also used in school A, while the teacher was using a rubric to assess students' reading fluency [26]. Asking the observed teacher about the reason she asked students to assess themselves and their peers, she said that: "employing peer and self-assessment gave the students a chance to evaluate and judge themselves and their peers' performance." Furthermore, the ReadTheory website was used to encourage students to read after school hours. At the same time, the site was also used to assess them. Notably, most of the assessments that were used during classroom observations were formative assessments. Significantly, the most frequent assessment strategies were observing students while they were reading and giving them appropriate feedback. It is important to point out here that the observed classes were regular reading classes, not assessment or testing classes. The formal reading assessment is conducted on specific dates.

The interviews provided a deeper insight into assessments of oral reading fluency. From the interviews, it was found that the summative assessment of oral reading fluency is conducted on specific dates during the academic year as was recommended by Rasinski [26]. However, the informal assessment is conducted daily and weekly through the teachers' observation, a self-assessment checklist, and sometimes a peer assessment checklist, which were also recommended to use by Rasinski [26]. From the interviews, most of the teachers used rubrics $[26,48,49]$ very often to assess students' oral reading fluency formally. The interviewed teachers in school B stated that: "using rubrics or checklists is much easier and faster than using the WCPM test." However, the teachers, who taught the American curriculum in school A, used the WCPM test [50-52]. Hence, some of the interviewed teachers in school A believed that the WCPM test is time-consuming 
$[26,50,51,52]$. Therefore, the teachers preferred using a rubric, as was observed. This finding is supported by Meeks and Austin's [34] conclusion, who found that conducting the WCPM is taking quite a chunk of the reading classes' time. In response to this claim, DiSalle and Rasinski [6] and Hudson, Lane, and Pullen [53] argued that the selected assessment tool should be based on the teachers' goals and areas of focus. In fact, the latest research believed that the WCPM test is accurate and reliable in measuring fluency and comprehension $[17,18]$.

\subsection{Is There a Match Between the Reading-Aloud Strategies and the Assessment Strategies Used?}

Generally speaking, in these two schools, the reading-aloud strategies stated in the document analysis were implemented in the observed classrooms. Obviously, there were more reading-aloud strategies applied in the school A classes more than what was found in the documents (lesson plans). However, teachers responded to this during the interview by stating that "the same plan is written for all classes of one grade. The purpose of the lesson plan is to guide teachers (in particular novice teachers). However, we adapt and change the plan to match students' levels and interests". The teachers had to pick up and modify the instructions for their classes. Also, some claimed that they are experienced teachers and do not need to follow the plan completely.

Concerning the assessment strategies stated in the documents, students' English textbooks for grade four and lesson plans, they were also implemented in the classroom to assess students' progress. However, the WCPM test stated in the student's textbooks in school A was not implemented in the observed classes for many reasons. One of the reasons uncovered during the interviews is that teachers use this test with students at the end of each theme. Another reason is due to the schools' decisions and the prepared schedules for the researcher's observations; it was not allowed for the researcher to attend any assessment classes. However, in school A, in one of the observed classes, the teacher assessed students' reading fluency by using a rubric. Generally, it was clear that teachers assess what they teach, and the assessment tools presented in the students' textbooks were conducted in the reading classes.

To sum up, there was a match between the reading-aloud strategies found in the documents and the reading-aloud observed in the classes. Also, it was the same for the assessment strategies mentioned in the students' textbooks and the assessments that teachers used in the classes. Furthermore, the assessment strategies and tools used matched and suited the reading-aloud strategies employed in the reading classes. In fact, the interviews did not only expose the match between the reading-aloud strategies and the assessment strategies but also revealed more reading-aloud strategies and assessment tools than what was investigated in the document analysis and what was observed in the reading classes. Additionally, the interviews showed that teachers were aware of utilizing different reading-aloud strategies and assessment strategies depending on the students' levels and stages of reading they were in. It was obvious how much focus was given to teach and assess oral reading fluency.

\section{Conclusions}

Reading fluency is once again a topic of interest. Opinions that are commonly held by the significance of teaching and assessing oral fluency must have further investigation. Without research-based evidence to support the idea of teaching and assessing oral reading fluency, it would be neglected. This was a preliminary study in UAE private schools. It aimed to explore and create a pathway to more advanced research on oral reading fluency, particularly in the UAE context, which has a limited number of studies in this area. Oral reading fluency should be clearly on the rise in the current trends of the UAE education. Therefore, directions for future research in the area of oral reading fluency must be considered in the near future. Based on the exploration of this skill in private schools, the outcomes would hopefully enlighten English teachers, educators and academicians, and curriculum designers in public schools about the effective and successful teaching practices that are used in private schools to help students improve their oral reading fluency.

It is important to point out that this study did not involve any experiment to investigate the impact of particular reading-aloud strategies on oral reading fluency. Further research should look thoroughly at the effects of some reading-aloud techniques on students' reading fluency. It would be worthwhile in future research to draw attention to the advantages and disadvantages that could be gained from specific reading-aloud strategies. Moreover, although this study explored the assessment strategies for oral reading fluency, it did not provide in-depth details about the procedures for conducting those assessments. There was not adequate information about how those assessment tools could be developed, designed, and implemented to assess students' oral reading fluency. Studies on a specific assessment method can take place, in which procedures and processes are clearly described and clarified for teachers to use and implement in classrooms. Research in the future could analyze textbooks used in a classroom and whether the structure of text facilitates reading comprehension and investigate if the strategies used in the classroom by teachers are a complement to the texts used. Interestingly, through the investigation of this study, it was found that there were some technological aids used to assist reading-aloud instructions, which this study did not aim to investigate. Therefore, it would be fascinating to investigate in detail how technology can improve students' oral reading fluency in future research. 


\section{REFERENCES}

[1] Rupley, W. H., Nichols, W. D., Rasinski, T. V., Paige, D., "Fluency: deep roots in reading instruction," Education Sciences, vol. 10, no. 6, p. 155, 2020. DOI: 10.3390/educsci10060155

[2] Lahmann, C., Steinkrauss, R., Schmid, M., "Speed, breakdown, and repair: an investigation of fluency in long-term second-language speakers of English," International Journal of Bilingualism, vol. 21, no. 2, pp. 229-241, 2017. DOI: 10.1177/1367006915613162

[3] Rasinski, T., "Fluency matters," International Electronic Journal of Elementary Education, vol. 7, pp. 3-12, 2014. https://www.iejee.com/index.php/IEJEE/article/view/60

[4] Rasinski, T., Padak, N., "Effective reading strategies: Teaching children who find reading difficult," Upper Saddle River, N.J., Merrill, 2000

[5] Tracey, D. H., Morrow, L. M., "Lenses on reading: An introduction to theories and models," New York, Guilford Press, 2012

[6] DiSalle, K., Rasinski, T., "Impact of short-term intense fluency instructions on students' reading achievement: a classroom-based teacher-initiated research study," Journal of Teacher Action Research, vol. 3, pp. 1-13, 2017. http://www.practicalteacherresearch.com/archive.html

[7] Blachowicz, Z., Lems, K., Rasinski, T. V., "Fluency instructions research-based best practices, New York, Guilford Press, 2012.

[8] Ontario., "Early reading strategy: The report of the expert panel on early reading in Ontario," Brantford, Ont: W. Ross MacDonald School Resource Services Library, 2009.

[9] Rasinski, T., "Essential readings on fluency," Newark, Del, International Reading Association, 2009.

[10] Huddle, S. M., "The impact of fluency and vocabulary instructions on the reading achievement of adolescent English language learners with reading disabilities," $\mathrm{Ph} . \mathrm{D}$. dissertation, University of Iowa, 2014. [Online]. Available: http://ir.uiowa.edu/etd/4650

[11] Al Jaffal, F, M., "The effect of repeated reading strategy on oral reading fluency of a fourth grade student with reading difficulties," M.S. thesis, UAEU, 2014. [Online]. Available: https://scholarworks.uaeu.ac.ae/cgi/viewcontent.cgi?article $=1112 \&$ context $=$ all $\_$theses

[12] Hussien, A. M., "The indicating factors of oral reading fluency of monolingual and bilingual children in Egypt," International Education Studies, vol. 7, pp. 75-90, 2014. DOI: $10.5539 /$ ies.v7n2p75

[13] Aldhanhani, R, Z., Abu-Ayyash, E., "Theories and research on oral reading fluency: What is needed?," Theory and Practice in Language Studies, vol. 10, no. 4, pp. 379-388, 2020. DOI: $10.17507 /$ tpls. 1004.05

[14] Samuels, S. J., "The method of repeated readings," The Reading Teacher, vol. 41, pp.756-760, 1979. https://www.jstor.org/stable/20194790

[15] Scriven, M., "The methodology of evaluation," in
Perspectives of Curriculum Evaluation, Chicago, Rand McNally, 1967, vol. 1, pp. 39-83.

[16] Jiang, X., "The role of oral reading fluency in ESL reading comprehension among learners of different first language backgrounds," The Reading Matrix, vol. 16, no. 2, pp.227242, 2016. https://eric.ed.gov/?id=EJ1115275

[17] Rubin, D. I., "Growth in oral reading fluency of Spanish ELL students with learning disabilities," Intervention in School and Clinic, vol. 52, pp. 34-38, 2016. DOI: $10.1177 / 1053451216630280$

[18] Al-Kharusi, K., "The effectiveness of repeated reading in reading fluency in English of grade four Omani students," M.S. thesis, University of Nottingham, Malaysia, 2014. [Online]. Available: https://www.nottingham.edu.my/searc h.aspx?search_keywords $=$ master\%20thesis

[19] Gorsuch, G.J., Taguchi, E., "Repeated reading for developing reading fluency and reading comprehension: The case of EFL learners in Vietnam," System, vol. 36, no. 2, pp. 253-278, 2008. DOI: 10.1016/j.system.2007.09.009

[20] Berg, K., Lyke, C., "Using repeated reading as a strategy to improve reading fluency at the elementary level," M.S. thesis, St. Xavier University, 2012. [Online]. Available: https://eric.ed.gov/?id=ED531173

[21] Flores-Saldana, M. E., "The positive connection between poetry and reading fluency in kindergarten through sixth grade classrooms," M.S. thesis, California State University, Stanislaus, 2016. [Online]. Available: https://scholarworks. calstate.edu/concern/theses/mp48sd441

[22] Calo, K. M., Woolard-Ferguson, T., Koitz, E., "Fluency idol: Using pop culture to engage students and boost fluency skills," The Reading Teacher, vol. 66, pp. 454-458, 2013. DOI: $10.1002 /$ TRTR. 1148

[23] Marcell, B., Ferraro, C., "So long, robot reader! A superhero intervention plan for improving fluency,' Reading Teacher, vol. 66 , no. 8 , pp. 607-614, 2013. DOI: $10.1002 / \operatorname{trtr} .1165$

[24] Black, A., "The effects of reader's theatre on reading comprehension and fluency of fifth-grade students," $\mathrm{Ph} . \mathrm{D}$. dissertation, Walden University, 2016. [Online]. Available: https://scholarworks.waldenu.edu/dissertations/1958

[25] Faatz, M. E., "The effects of readers' [sic] theater on the fluency and comprehension of students reading below grade level," M.S. thesis, S.U.N.Y College at Brockport, 2009. [Online]. Available: http://digitalcommons.brockport.edu/e hd_theses/692

[26] Rasinski, T., "Assessing reading fluency," ERIC Clearinghouse, 2004.

[27] Rowen, D., Biggs, D., Watkins, N., Rasinski, T., "Choral reading theater: Bridging accuracy, automaticity, and prosody in reading fluency across an academic unit of study," Journal of Teacher Action Research, vol. 1, pp. 53-69, 2015.http://www.practicalteacherresearch.com/arch ive.html

[28] Schneider, K., "An investigation into the effectiveness of paired reading with the incorporation of additional error corrective procedures," B.S thesis, Edith Cowan University, 2007. [Online]. Available: https://ro.ecu.edu.au/theses hon s/1138/ 
[29] Gerdes, S. A., "The effects of repeated reading, paired reading, and demonstration on reading fluency," M.S. thesis, Grand Valley State University, 2000. [Online]. Available: http://scholarworks.gvsu.edu/theses/495

[30] Creswell, J., "Educational research: planning, conducting and evaluating quantitative and qualitative research," 2nd ed, Pearson Education, Inc, 2005.

[31] Padak, N., Rasinski, T. V., "Evidence-based instructions in reading: A professional development guide to fluency," Boston, MA: Pearson/Allyn and Bacon, 2008.

[32] Ehri, L., McCormick, S, "Phases of word learning: Implications for instructions with delayed and disabled readers," Reading and Writing Quarterly: Overcoming Learning Difficulties, vol. 14, no. 2, pp. 135-164, 1998. DOI: $10.1080 / 1057356980140202$

[33] Blevins, W., "Building fluency: Lessons and strategies for reading success," New York: Scholastic, 2001.

[34] Meeks, L. L., Austin, C. J., "Literacy in the secondary English classroom: Strategies for teaching the way kids learn," Boston, Allyn and Bacon, 2003.

[35] Rasinski T.V., Rupley W.H., Paige D.D., Nichols W.D., "Alternative text types to improve reading fluency for competent to struggling readers," International Journal of Instruction, vol. 9, pp. 163-178, 2016. DOI: 10.12973/iji.2016.9113a

[36] Wallot S., Van Rooij M., Hollis G., "Connected text reading and differences in text reading fluency in adult readers," PLoS ONE, vol. 8, pp. 1-22, 2013. DOI: 10.1371/journal.pone.0071914

[37] Tankersley, K., "Threads of reading: strategies for literacy development," Alexandria, Va, Association for Supervision and Curriculum Development, 2003.

[38] Chang, A. C.-S., "The effect of a timed reading activity on EFL learners: speed, comprehension, and perceptions," Reading in a Foreign Language, vol. 22, pp. 284-303, 2010. https://eric.ed.gov/?id=EJ901548

[39] Devaney, K., Foord, K., Anne, D., "A case study of four high school ESL students' oral reading fluency and affect," M.S. thesis, Minnesota State University, Mankato, 2012. [Online]. Available: http://cornerstone.lib.mnsu.edu/etds/9 6

[40] Jeon, E. H., "Oral reading fluency in second language reading," Reading in a Foreign Language, vol. 24, pp. 186-208, 2012. https://eric.ed.gov/?id=EJ994853

[41] Yildiz, M., Yildirim, K., Ates, S., Cetinkaya, C., “An evaluation of the oral reading fluency of 4th graders with respect to prosodic characteristic," International Journal of Human Sciences, vol. 6, no. 1, pp. 353-360, 2009. https://www.j-humansciences.com/ojs/index.php/ijhs/articl e/view/622

[42] Veenendaal, N. J., Groen, M. A., Verhoeven, L., "The role of speech prosody and text reading prosody in children's reading comprehension," British Journal of Educational Psychology, vol. 84, pp. 521-536, 2014. DOI: 10.1111/bjep.12036

[43] Rasinski, T. V., Pacific Resources for Education and Learning, "Assessing reading fluency," Honolulu, Hawai'i: Regional Educational Laboratory at Pacific Resources for Education and Learning, 2004.

[44] Aldhanhani, Z.R., "The role of computerized games in teaching English curriculum- UAE perspective: Investigation of the impact of using computerized games on students' acquisition of English vocabulary in kindergarten level two," TESOL Arabia Conference, Dubai, UAE, 2015.

[45] Reichenberg, J., "The use of iPads to facilitate growth in reading comprehension skills of second grade students," Ph.D dissertation, Liberty University, 2014. [Online]. Available: http://digitalcommons.liberty.edu/doctoral/942

[46] Armbruster, B. B., Lehr, F., Osborn, J., Adler, C. R., National Institute for Literacy (U.S), "Put reading first: The research building blocks of reading instruction: Kindergarten through grade 3," 2nd ed, Washington, D.C. National Institute for Literacy, 2003.

[47] Count, P., "Utilizing voice recognition software to improve reading fluency of struggling adolescent readers," Ph.D. dissertation, ECU, Research Online, Perth, Western Australia, 2016. [Online]. Available: https://ro.ecu.edu.au/t heses/1799/

[48] Xu, Jing., "Predicting ESL learners' oral proficiency by measuring the collocations in their spontaneous speech," Ph.D. dissertation, Iowa State University, 2015. [Online]. Available: https://lib.dr.iastate.edu/etd/14875/

[49] Top of FormYoon, S.-Y., "Automated assessment of speech fluency for L2 English learners," Ph.D. dissertation, University of Illinois at Urbana-Champaign, 2009. [Online]. Available: https://eric.ed.gov/?id=ED526010

[50] Cummings, K. D., Park, Y., Schaper, H. A. B., "Form effects on DIBELS next oral reading fluency progressmonitoring passages," Assessment for Effective Intervention, vol. 38, pp. 91-104, 2013. DOI: $10.1177 / 1534508412447010$

[51] Rasinski, T., Padak, N., "3-Minute reading assessments: Word recognition, fluency and comprehension," New York, Scholastic Teaching Resources, 2005.

[52] York, M., Foorman, B., Santi, K., Francis, D., "Effects of technology enhancements and type of teacher support on assessing Spanish-speaking children's oral reading fluency in second grade," Assessment for Effective Intervention, vol. 37, pp. 3-16, 2011. DOI: 10.1177/1534508411402983

[53] Hudson, R., Lane, H., Pullen, P., "Reading fluency assessment and instruction: What, why, and how?," The Reading Teacher, vol. 58, pp. 702-714, 2005. DOI: 10.1598/RT.58.8.1

\footnotetext{
${ }^{\mathrm{i}}$ Part of the manuscript content is from my $\mathrm{PhD}$ thesis, which has been submitted to the British University in Dubai.
} 